\title{
Expression of cell adhesion molecules, chemokines and chemokine receptors involved in leukocyte traffic in rats undergoing autoimmune orchitis
}

\author{
V A Guazzone, P Jacobo, B Denduchis and L Lustig \\ Facultad de Medicina, Instituto de Investigaciones en Reproducción, Universidad de Buenos Aires, Paraguay 2155 \\ piso 10, C1121 ABG Ciudad Autónoma de Buenos Aires, Argentina
}

Correspondence should be addressed to VA Guazzone; Email: ciruba@fmed.uba.ar

\begin{abstract}
The testis is considered an immunologically privileged site where germ cell antigens are protected from autoimmune attack. Yet in response to infections, inflammatory diseases, or trauma, there is an influx of leukocytes to testicular interstitium. Interactions between endothelial cells (EC) and circulating leukocytes are implicated in the initiation and evolution of inflammatory processes. Chemokines are a family of chemoattractant cytokines characterized by their ability to both recruit and activate cells. Thus, we investigated the expression of CCL3, its receptors, and adhesion molecules CD31 and CD106 in an in vivo model of experimental autoimmune orchitis (EAO). In EAO, the highest content of CCL3 in testicular fluid coincides with onset of the disease. However, CCL3 released in vitro by testicular macrophages is higher during the immunization period. The specific chemokine receptors, CCR1 and CCR5, were expressed by testicular monocytes/macrophages and an increased number of CCR5+ cells was associated with the degree of testicular lesion. EC also play an essential role by facilitating leukocyte recruitment via their ability to express cell surface adhesion molecules that mediate interactions with leukocytes in the bloodstream. Rats with EAO showed a significant increase in the percentage of CD31+ EC that upregulate the expression of CD106. The percentage of leukocytes isolated from peripheral blood and lymph nodes expressing CD49d (CD106 ligand) also increases during orchitis. These data suggest that cell adhesion molecules, in conjunction with chemokines, contribute to the formation of a chemotactic gradient within the testis, causing the leukocyte infiltration characteristic of EAO histopathology.

Reproduction (2012) 143 651-662
\end{abstract}

\section{Introduction}

Testicular immune privilege contributes to protect spermatogenic cells from the host immune response, and failure of control leads to autoimmune infertility in the form of sperm antibodies or autoimmune orchitis (Tung et al. 2000). These reactions account for $5-10 \%$ of the cases of male infertility in the developed world, but can be considerably higher in populations where reproductive health measures are deficient or absent (Meinhardt \& Hedger 2011).

Experimental autoimmune orchitis (EAO) in the rat is a useful model of chronic inflammation for elucidating pathogenic mechanisms involved in testicular damage. EAO is characterized by interstitial inflammatory cell infiltrate, apoptosis, and sloughing of germ cells (Jacobo et al. 2011a). Quantitative and phenotypic analyses of testis-infiltrating cells revealed an increased number of macrophages, dendritic cells (Rival et al. 2006a, 2008), and T cell subsets that include effector Th1 and Th17 cells as well as Foxp3+ regulatory T cells (Jacobo et al. 2009, 2011b).
During inflammation, leukocytes are recruited into tissues by adhesion molecules and chemokines. The specificity of leukocyte homing is regulated by the combination of chemokines in the microenvironment, adhesion molecules on the endothelium, and leukocyte receptors for these chemokines and adhesion molecules. Signals generated at an inflammation site cause circulating leukocytes to respond by rolling, arrest, and then transmigration through the endothelium (reviewed by Muller (2011)).

Chemokines, or chemotactic cytokines, are classically known as regulators of leukocyte infiltration and classified into three primary groups based on structural motifs, which, in turn, confer functional specificity. The largest family consists of CC chemokines, or $\beta$-chemokines, so named because the first two of the four cysteine residues in these molecules are adjacent to each other. CC chemokines attract mononuclear cells to sites of chronic inflammation. The most thoroughly characterized CC chemokine is monocyte chemoattractant protein-1 (MCP-1 or CCL2 in the systematic 
nomenclature). It is a potent agonist for monocytes, dendritic cells, memory T cells, and basophils. Other CC chemokines include macrophage inflammatory protein (MIP)-1 $\alpha / C C L 3$, MIP-1 $\beta / C C L 4$, and RANTES/CCL5 (Zlotnik \& Yoshie 2000).

We previously described an increase of CCL2 (Guazzone et al. 2003) and CCL4 (Guazzone et al. 2009) in the testis of rats with orchitis. The highest CCL2 concentration was associated with the highest number of mononuclear cells expressing CCL2 receptor (CCR2) detected within the testicular interstitium of EAO rats (Guazzone et al. 2003). Chemokines affect cells by activating surface receptors that are seven-transmembrane domain G-protein-coupled receptors and leukocyte responses to particular chemokines are determined by their complement of chemokine receptors. Chemokine binding to the receptor activates signaling cascades that culminate in the rearrangement, change in shape, and cell movement of actin (Thelen \& Stein 2008).

Leukocyte-endothelial adhesion molecules are grouped into three families: 1) selectins, a family of three carbohydrate-recognizing molecules involved in the rolling of leukocytes on the luminal side of the endothelium; 2 ) integrins, $\alpha$ and $\beta$ chain heterodimers (e.g. $\alpha 4$ (CD49d)/ $\beta 1$ complex) that mediate cell adhesion to extracellular matrix proteins or cell-cell interactions via the immunoglobulin superfamily; and 3) this immunoglobulin superfamily includes intercellular cell
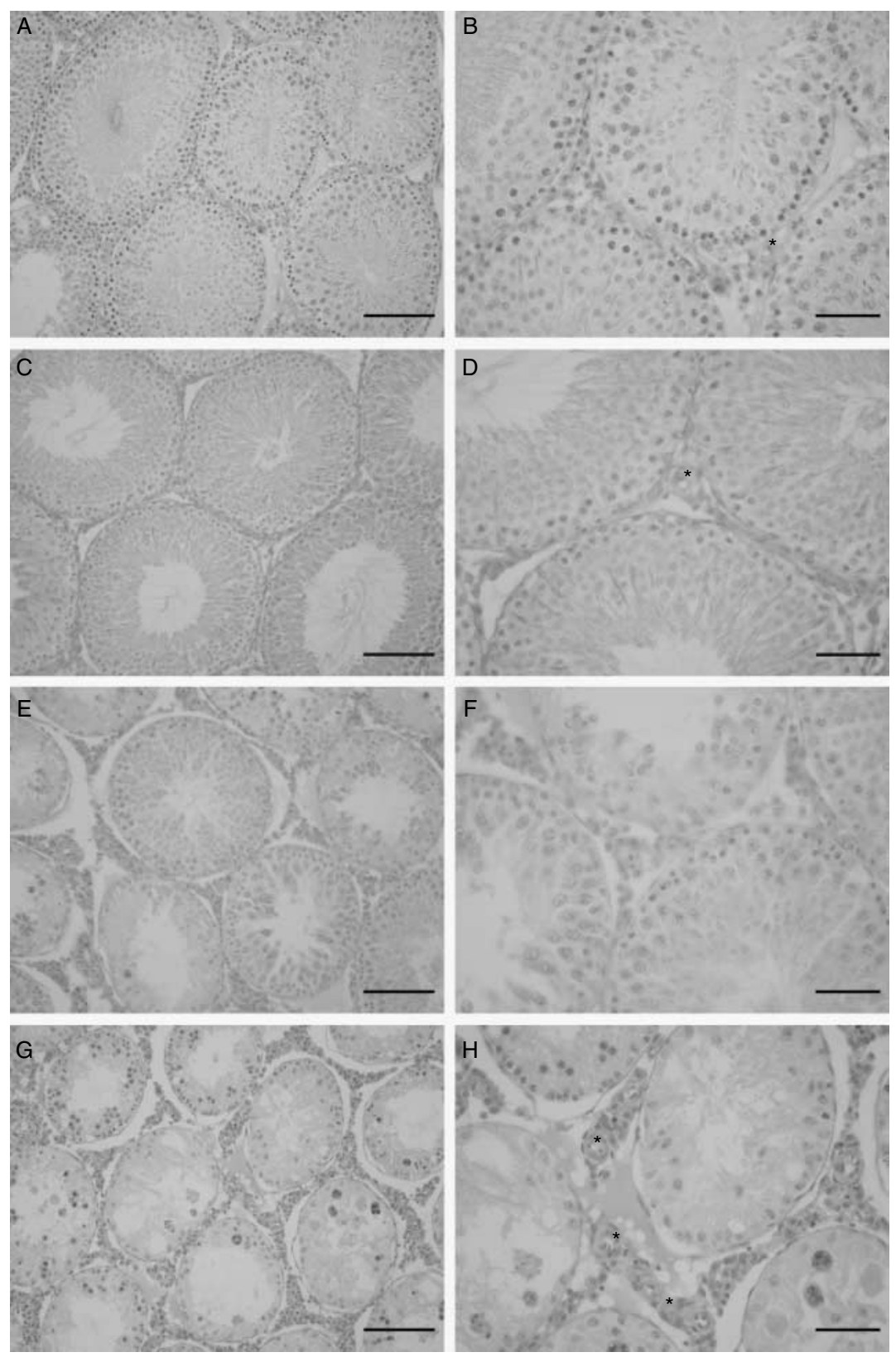

Figure 1 Testicular histopathology. Testis sections from experimental rats with focal (50 days, $\mathrm{E}$ and $\mathrm{F}$ ) and severe orchitis ( 100 days, $\mathrm{G}$ and $\mathrm{H}$ ) show seminiferous tubules with different degrees of germ cell degeneration and sloughing. Numerous small blood vessels $(*)$ are seen in the interstitium of rats with severe orchitis. Control rats ( $\mathrm{A}$ and $\mathrm{B}$ ) and experimental rats killed on day $30(C$ and $D)$ show normal spermatogenesis and interstitial tissue with few small blood vessels $\left({ }^{*}\right)$. Scale bars indicate $100 \mu \mathrm{m}$ for $(\mathrm{A}, \mathrm{C}, \mathrm{E}$, and $\mathrm{G})$ and $50 \mu \mathrm{m}$ for $(B, D, F$, and $H)$. 
adhesion molecules 1-5 (ICAM) vascular cell adhesion molecule-1 (VCAM-1/CD106) and junctional adhesion molecule (JAMs). Yet another important adhesion receptor of the immunoglobulin superfamily involved in leukocyte recruitment is the endothelium marker platelet/endothelial cell (EC) adhesion molecule (PECAM-1/CD31) (Langer \& Chavakis 2009).

The purpose of this study was to detect the main chemokines and cell adhesion molecules involved in leukocyte extravasation in the testicular interstitium during the development of autoimmune orchitis. Specifically, we analyzed CCL3, its receptors, CCR1 and CCR5, and CD106 and CD31 expression in the testis of EAO rats.

\section{Results}

\section{Histopathology}

Ninety percent of rats in the experimental (E) group developed autoimmune orchitis. As previously described (Doncel et al. 1989), the testicular lesion, focal by 50 days and severe by 100 days, was characterized by an interstitial mononuclear cell infiltrate composed mainly of macrophages and lymphocytes intermingled with Leydig cells. Different degrees of germ cell sloughing were observed in the seminiferous tubules (ST). In rats with severe orchitis, we observed large areas of aspermatogenic ST in which only spermatogonia and Sertoli cells were attached to the tubular wall. No rats in normal (N) and control (C) groups revealed pathological alterations of the testis. On the basis of histopathologic observations, E rats were grouped as 7-30 days (no testicular damage) corresponding to the immunization period, 50 days (focal orchitis) and 100 days (severe orchitis).

Evaluation of the number of testicular vessels revealed a significant increase of these structures in the testicular interstitium of rats with orchitis that correlated with the degree of histopathologic damage (Fig. 1; N: 59.17 \pm 2.12 , C7-30 days: 58.78 \pm 1.20, E7-30 days: 56.57 \pm 2.73 , C50 days: $59.43 \pm 2.31$, E50 days: $95.71 \pm 6.86^{\mathrm{a}, \mathrm{b}, \mathrm{c}}$, C100 days: $66.80 \pm 2.78$, E100 days: $143.85 \pm 10.06^{\mathrm{de}, \mathrm{e}} \mathrm{f}^{\prime}$. ${ }^{\mathrm{a}} P=0.01$ vs $\mathrm{N},{ }^{\mathrm{b}} P=0.0023$ vs $\mathrm{C} 50$ days, ${ }^{\mathrm{c}} P=0.0012$ vs E7-30 days, ${ }^{\mathrm{d}} P<0.0001$ vs $\mathrm{N}$ and $\mathrm{E} 7-30$ days, ${ }^{\mathrm{e}} P=0.0005$ vs $\mathrm{C} 100$ days, ${ }^{\mathrm{f}} P=0.0063$ vs $\mathrm{E} 50$ days).

\section{Determination of CCL3}

The concentration of CCL3 in testicular fluid (TF), testicular macrophage-conditioned media (TMCM), and serum was measured by ELISA in N, C, and $\mathrm{E}$ rats. CCL3 concentration in TF was similar comparing $\mathrm{C}$ and $\mathrm{E}$ groups during the immunization period (7-30 days), whereas during disease onset (50 days) a significant increase in CCL3 concentration was observed in E group in contrast to $\mathrm{C}$ group. This increase was not sustained during the severe phase of disease since its level dropped on day 100 (Fig. 2). CCL3 concentration in N group was similar to $C$ group (data not shown).

Production of CCL3 by testicular macrophages isolated from rats of E group killed on days 7 and 30 was higher compared to $\mathrm{C}$ group. In contrast, CCL3 concentration was lower in TMCM from rats with orchitis (50 and 100 days; Fig. 3).

Serum concentrations of CCL3 of $\mathrm{C}$ and $\mathrm{E}$ groups were similar (Fig. 4) with values comparable to $\mathrm{N}$ group.

\section{Expression of CCR1 and CCR5}

CCR 1 and CCR5 are CCL3 receptors. In order to identify which cells within the testis express these chemokine receptors, we used an immunohistochemical technique in testis sections from N, C, and E groups. Mononuclear cells with macrophage like morphology present in the testicular interstitium expressed CCR1 (Fig. 5) or CCR5 (Guazzone et al. 2009). No staining was observed in sections incubated with isotype IgG negative control instead of primary antibody. We quantified the number of CCR1+ or CCR5+ cells per testis on different days after the first immunization. The number of CCR1+ cells was similar in the different groups studied (Table 1). However, the number of CCR5+ cells progressively increased in $\mathrm{E}$ group compared to $\mathrm{N}$ and $\mathrm{C}$ groups, reaching a maximum on day 100 (Table 2). These results suggest a correlation between the degree of testicular lesion and CCR5 expression. The number of CCR5+ cells observed in $\mathrm{C}$ and $\mathrm{N}$ groups was similar (Table 2). In order to confirm that macrophages express CCR1 and CCR5 receptors, we performed a double immunofluorescence on isolated testicular macrophages using these markers simultaneously with ED1 or ED2. We observed that most of the recently arrived ED1+ monocytes/ macrophages within the testis as well as ED2+ resident macrophages express CCR1 (Fig. 6) or CCR5.

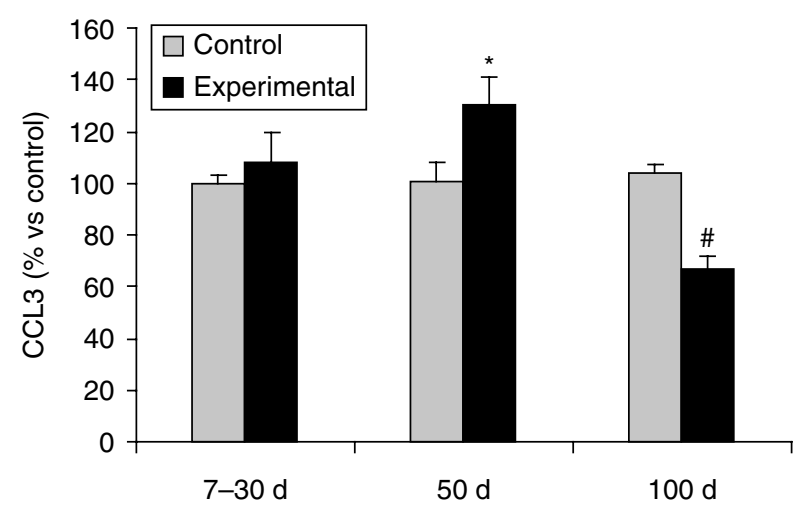

Figure 2 Measurement of CCL3 by ELISA in TFs. Values are means \pm S.E.M. of 6 rats/group per day after the first immunization. $d=$ days after the first immunization. ${ }^{*} P=0.0336$ vs respective $C,{ }^{*} P<0.0001$ vs respective $C$. 


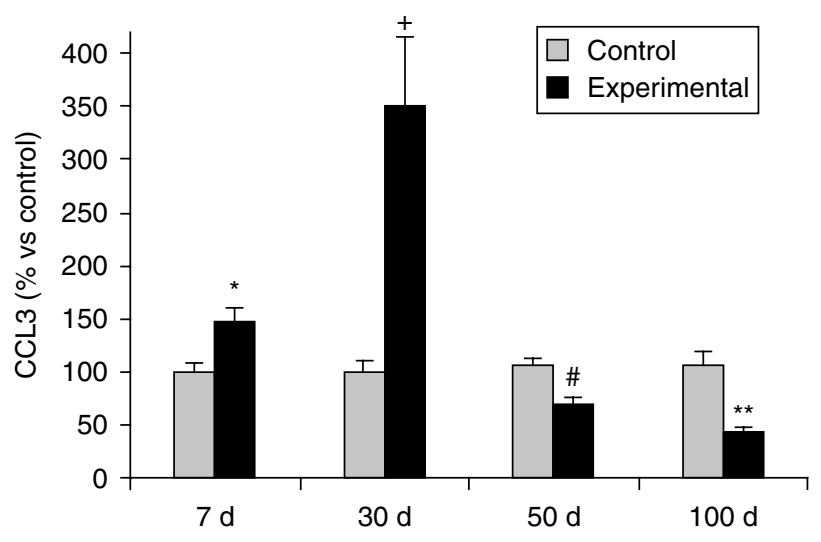

Figure 3 Measurement of CCL3 by ELISA in conditioned media from testicular macrophages. Values are expressed as percentage of respective $C$ group and means \pm s.E.M. of 6 rats/group per day after the first immunization. $d=$ days after the first immunization. Data of experimental rats are presented as independent histograms to show the different rate of increase during the immunization period. ${ }^{*} P=0.0098$ vs $C,{ }^{+} P=0.0008$ vs $C,{ }^{\#} P=0.0056$ vs $C,{ }^{* *} P<0.0001$ vs $C$.

\section{Leukocyte chemotaxis to CCL3}

In order to evaluate the migration ability of peripheral blood mononuclear cells (PBMC) and purified mononuclear cells from popliteal lymph nodes (LNC) in response to $\mathrm{CCL} 3$ we performed in vitro chemotaxis assay. Results showed that PBMC and LNC of rats with focal ( 50 days) and severe ( 100 days) orchitis migrated in response to CCL3 compared to medium alone (Table 3).

\section{CD31 and CD106 expression on testicular EC}

The next objective was to study CD31 and CD106 expression in order to ascertain participation of testicular microvascular endothelium in leukocyte extravasation during EAO. Since EC are a minor cell population within the interstitial cells, we decided to obtain an enriched EC cell fraction by anti-CD31 immunomagnetic separation. Because CD31 is expressed constitutively on the surface of $\mathrm{EC}$ but is also expressed weakly on many peripheral leukocytes, CD31 and CD106 expression were assessed on CD45-negative gate (Fig. 7A). An increased percentage of $\mathrm{EC}(\mathrm{CD} 31+\mathrm{CD} 45-)$ was observed in rats with orchitis (50-100 days) compared to $\mathrm{C}$ and $\mathrm{N}$ groups. The percentage was similar in $\mathrm{C}$ and $\mathrm{E}$ groups during the immunization period (7-30 days; Fig. 7B).

Further, analysis of CD106 on the surface of EC showed that CD106 expression level in rats with orchitis (100 days) is higher than in $C$ rats, but similar levels were observed in $\mathrm{C}$ and $\mathrm{E}$ groups during the immunization period. No rats from $\mathrm{N}$ group expressed CD106 (Fig. 7C).

\section{CD49d expression on PBMC and LNC}

CD106 interacts with VLA-4 (an integrin $\alpha 4$ (CD49d)/ integrin $\beta 1$ complex). We examined by flow cytometry the expression of CD49d molecules on the surface of PBMC and LNC isolated from $\mathrm{C}$ and $\mathrm{E}$ rats on different days after the first immunization. CD49d molecules were found to be expressed on PBMC and LNC in every group studied. Based on expression levels of CD49d, we are able to define two subsets of CD49d+ cells (hereby referred to as CD49d low and CD49d $\mathrm{d}^{\text {high }}$ ). A significant increase in the percentage of CD49d ${ }^{\text {high }}$ cells was found during the testicular damage period. However, the percentage of CD49d+ cells was similar in C and E groups (Fig. 8).

\section{Discussion}

EAO is a robust model to investigate inflammatory-based testicular impairment, which ranks as a significant cause of male infertility. In previous works, we extensively described the testicular histopathology of rats with EAO (first described in Doncel et al. (1989)). However, we have not previously highlighted the process of neovascularization occurring in the testes of these rats. The identification of angiogenic factors such as vasculature endothelial growth factor, hypoxia-inducible factor $1 \alpha$, cytokines, or androgens will undoubtedly enhance understanding of the increased vascularization observed in EAO testis. In seasonal breeders, increased angiogenesis and rapid renewal of microvasculature is fundamental for physiologic testicular recrudescence (Mayerhofer et al. 1989). Sertoli cells (which remain attached to the ST walls even in rats with severe EAO) and Leydig cells have been shown to have an angiogenic function (Collin \& Bergh 1996, Golat \& Cameron 2008). Leukocyte infiltration into the testicular interstitium is a key process in the pathogenesis of testicular inflammation. In our previous studies, we reported the involvement of CCL2 and CCL4 chemokines and the activated, hyaluronan-binding form of CD44 molecule in the homing of lymphocytes and monocytes into testes of rats with autoimmune orchitis (Guazzone et al. 2003, 2005, 2009). In the present work we studied the

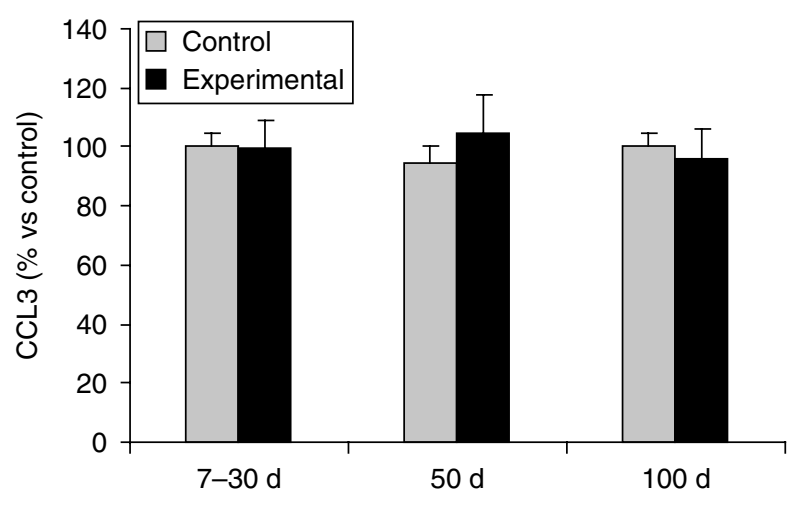

Figure 4 Measurement of CCL3 by ELISA in serum. Values are means \pm S.E.M. of 6 rats/group per day after the first immunization. $d=$ days after the first immunization. 
expression of CCL3 chemokine and its receptors, CD31 and CD106 adhesion molecules, aiming to improve the understanding of the migration of leukocytes from the vascular lumen into inflamed testicular tissue.

The process of leukocyte migration begins with generation of inflammatory mediators such as chemokines and cytokines and upregulation of EC adhesion


Figure 5 CCR1 immunoreactivity in cryostat testis sections. CCR1+ cells are scattered in the testicular interstitium of both, $C(A)$ and $E(B)$ rats killed at 100 days after first immunization. Omission of primary antibody shows negative staining in C. Scale bars indicate $50 \mu \mathrm{m}$. molecule expression supporting the initial attachment of leukocytes to EC and further extravasation. The limited information concerning the action of CC-chemokines in the testis arises from in vitro studies using testicular cell primary cultures. Using an immunohistochemical technique with an anti-human CCL3 antibody, Hakovirta et al. (1994) detected CCL3 in both rat germ and Leydig cells in contrast with Aubry et al. (2000) who observed no CCL3 mRNA expression in Leydig, Sertoli, peritubular, or germ cells. We used an in vivo model to investigate the role of adhesion molecules and chemokine production in the course of an autoimmune orchitis. The increase of CCL3 content in TF of rats with focal orchitis and the lack of differences in serum CCL3 concentrations in $\mathrm{N}, \mathrm{C}$, and $\mathrm{E}$ rats indicates local production in the male reproductive tract. The CCL3 released in vitro by testicular macrophages from $\mathrm{E}$ rats is significantly higher than in $\mathrm{C}$ rats during the immunization period ( 7 and 30 days). This upregulation in the CCL3 macrophage production is not reflected in the testis where TF ELISA results showed a significant increase of CCL3 content in the E group only during disease onset (50 days). We may speculate that macrophages are immune cells that respond early to inflammatory stimuli by releasing CCL3. When the disease was severe (100 days) we observed a decrease in CCL3 content in TF and TMCM. This CCL3 temporal expression is different to our previous CCL2 results in which testicular increase of CCL2 content is maintained during the severe phase of the disease (Guazzone et al. 2003). These differences strongly suggest differential and possibly temporal roles of chemokines in the regulation of leukocyte transendothelial migration in testicular inflammation. In this regard, a temporal regulation of chemokine production has been reported in the inflamed synovium (Szekanecz et al. 2000) and in the central nervous system (Kennedy et al. 1998, Chui \& DoroviniZis 2010). CCL3 production showed a very early increase preceding clinical symptoms, whereas CCL2 was involved in the later phase of the disease.

The magnitude of the cellular response elicited by chemokines is dictated by the level of receptor expression at the plasma membrane, a site where the balance of finely tuned endocytic and recycling pathways occurs. The chemokine CCL3 is a ligand for chemokine receptors CCR1 and CCR5, and ED1+ monocytes/macrophages and ED2+ resident macrophages present in the testicular interstitium express CCR1 and CCR5. A constitutively higher number of CCR1+ cells are detected in the different groups compared to CCR5. However, no significant changes in CCR1 expression were observed throughout the whole course of the disease. In contrast, the number of CCR5+ cells increased during focal and severe orchitis as we previously showed for CCR2 (Guazzone et al. 2003). These results suggest that CCR2 and CCR5 may sustain inflammatory changes whereas CCR1 might play a 
Table 1 Number $\left(\times 10^{6}\right)$ of CCR $1+$ cells/testis of rats.

\begin{tabular}{|c|c|c|c|c|c|}
\hline \multirow[b]{2}{*}{ Days $^{a}$} & \multirow[b]{2}{*}{ Normal $(\mathrm{N})$} & \multirow[b]{2}{*}{ Control (C) } & \multirow[b]{2}{*}{ Experimental $(\mathrm{E})$} & \multicolumn{2}{|c|}{ Testicular damage } \\
\hline & & & & Control (C) & Experimental $(\mathrm{E})$ \\
\hline & $2.73 \pm 0.24$ & & & - & - \\
\hline $7-30$ & & $1.77 \pm 0.186$ & $1.91 \pm 0.21$ & - & - \\
\hline 50 & & $2.45 \pm 0.30$ & $2.10 \pm 0.20$ & - & \pm \\
\hline 100 & & $3.13 \pm 0.33$ & $2.77 \pm 0.20$ & - & $+1++$ \\
\hline
\end{tabular}

Data were obtained by counting CCR $1+$ cells in testis sections of 6 rats/group per day. Values are means \pm s.E.M. Testicular damage is scored as, \pm+ , and ++ indicating few foci, numerous foci, or large areas of seminiferous tubules with germ cell sloughing respectively.

a'Days after first immunization.

physiological role in the initial recruitment of leukocytes into the testis. Also, chemotaxis assays demonstrated that leukocytes isolated from peripheral blood and LN of rats with orchitis migrated in response to CCL3. CCR5 is also the receptor for the chemokine CCL4. We previously demonstrated CCL4 expression in the walls of testicular blood vessels of EAO rats consistent with the high concentration of CCL4 detected in their TF (Guazzone et al. 2009).

CD31 is a molecule expressed on most leukocyte subsets, platelets, and on EC where its expression is largely concentrated at adjacent cell junctions. We focused on CD31 expression in testicular EC. The percentage of CD31+ EC increased in the testis of rats with orchitis compared to $\mathrm{N}$ and $\mathrm{C}$ groups consistent with the increased number of testicular blood vessels observed by histopathology. CD106 expression was also upregulated on $\mathrm{CD} 31+\mathrm{EC}$ isolated from testis of rats with orchitis, whereas $\mathrm{EC}$ isolated from $\mathrm{N}$ groups did not express CD106. Our previous results demonstrating by western blot analysis a significant increase of CD106 expression in the testis of EAO rats (Lustig 1998) allow us to speculate that this increase is associated with the increased number of testicular EC. Other authors reported that mouse (Sainio-Pöllänen et al. 1997) and human (Veräjänkorva et al. 2002) Leydig cells constitutively express CD106. In contrast to peripheral LN, EC at inflammation sites require stimulation of adhesion molecule expression that is induced by several mediators including locally produced cytokines, high levels of reactive oxygen species (ROS), turbulent blood flow at vessel bifurcations, or microbial stimulation of endothelial toll-like receptors. Thus, microenvironment stimuli regulate the specificity of leukocyte recruitment (Cook-Mills et al. 2010). In fact testicular immune cells secrete proinflammatory cytokines such as TNF- $\alpha$ (Suescun et al. 2003) and IL6 (Rival et al. 2006b), and nitric oxide (NO) production and $\mathrm{NO}$ synthase activity increased in testis of EAO compared to $\mathrm{C}$ and $\mathrm{N}$ rats (Jarazo Dietrich et al. 2010).

CD106 is involved in the firm adhesion to the endothelium of monocytes and lymphocytes bearing integrin CD49d. We observed an increase in the percentage of CD49d+ cells isolated from peripheral blood and draining LN of rats with orchitis. If leukocytes express CD49d and EC express CD106, clustering of CD106 also stimulates an increase in cytosolic free calcium, activation of Rac-1, and production of ROS in EC. The net result is the loosening of EC junctions facilitating transendothelial migration (Muller 2011).

On the basis of our previous and present data, our results suggest that the chemokines and cell adhesion molecules analyzed are part of an amplification circuit of the immune cell response essential for leukocyte recruitment and induction of severe autoimmune orchitis, in the context of chronic inflammation. We propose that during EAO development, leukocyte extravasation within the testis begins with initial contact between the activated form of CD44 on lymphocytes and its major ligand hyaluronan on endothelium (Guazzone et al. 2005). Then CCL3 and CCL2 chemokines (Guazzone et al. 2003) expressed by testicular cells

Table 2 Number $\left(\times 10^{6}\right)$ of CCR5+ cells/testis of rats.

\begin{tabular}{|c|c|c|c|c|c|}
\hline \multirow[b]{2}{*}{ Days $^{a}$} & \multirow[b]{2}{*}{ Normal (N) } & \multirow[b]{2}{*}{ Control (C) } & \multirow[b]{2}{*}{ Experimental (E) } & \multicolumn{2}{|c|}{ Testicular damage } \\
\hline & & & & Control (C) & Experimental $(\mathrm{E})$ \\
\hline & $0.58 \pm 0.12$ & & & - & - \\
\hline $7-30$ & & $0.46 \pm 0.09$ & $1.53 \pm 0.14^{*, \dagger}$ & - & - \\
\hline 50 & & $0.92 \pm 0.25$ & $2.63 \pm 0.42^{\ddagger, \S}$ & - & \pm \\
\hline 100 & & $0.88 \pm 0.38$ & $4.87 \pm 0.24 \|$, & - & $+\overline{l+}+$ \\
\hline
\end{tabular}

Data were obtained by counting CCR5 + cells in testis sections of 6 rats/group per day. Values are means \pm s.E.M. Testicular damage is scored as \pm , + , and ++ indicating few foci, numerous foci, or large areas of seminiferous tubules with germ cell sloughing respectively. ${ }^{*} P=0.0008$ vs $\mathrm{N}$;

${ }^{\dagger} P \leq 0.0001$ vs $C 7-30$ days; ${ }^{\ddagger} P=0.0089$ vs $C 50$ days; ${ }^{\xi} P<0.0001$ vs $N ;{ }^{\|} P<0.0001$ vs $C 100$ days and $N ;{ }^{\natural} P=0.0007$ vs $E 50$ days.

a Days after first immunization. 

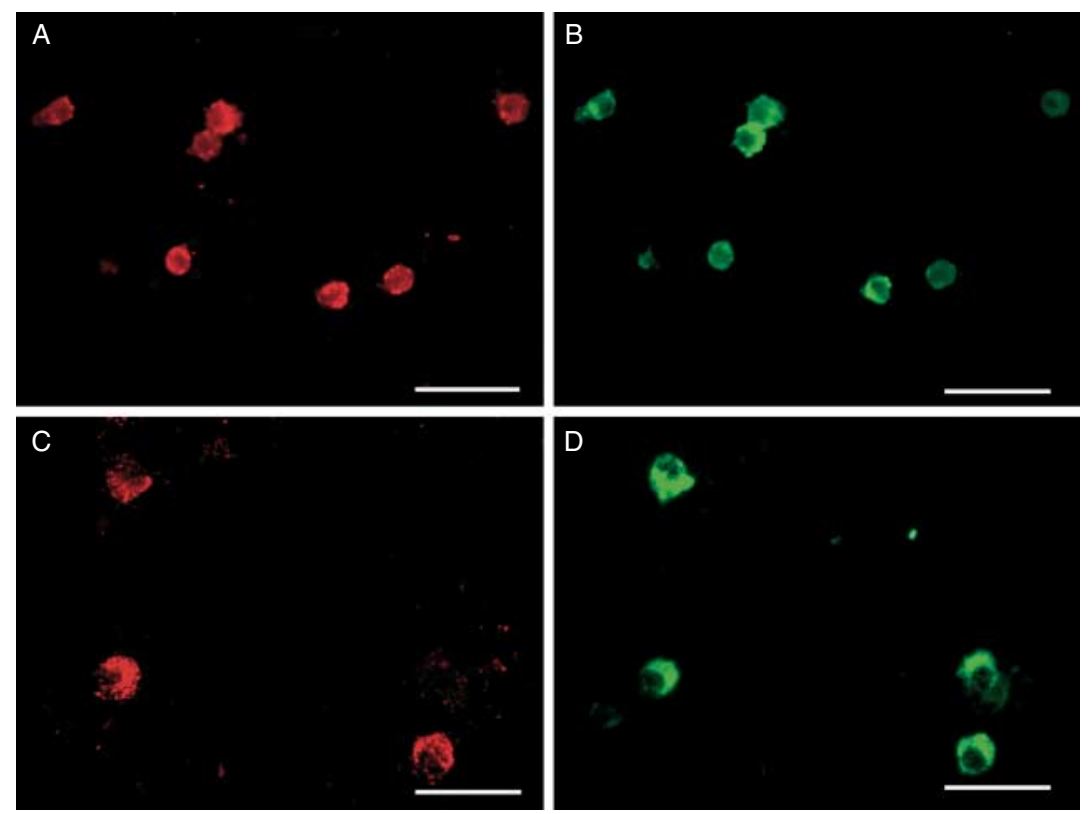

Figure 6 Colocalization of CCR1 and ED1+ or $\mathrm{ED} 2+$ macrophages in isolated testicular macrophages from a rat with autoimmune orchitis. Secondary antibodies conjugated with FITC were used as ED1 and ED2 markers and with Rhodamine for CCR1 expression. All ED1+ macrophages (D) and ED2+ (B) express CCR1 (A and C). Results were similar for CCR5 (data not shown). Scale bars indicate $20 \mu \mathrm{m}$. might convert leukocyte rolling under endothelium flow into cell arrest. Ransohoff (2009) established that the first signal, delivered by chemokines immobilized on the luminal surface of $\mathrm{EC}$, helps to convert leukocyte rolling into arrest by inducing Rho GTPase family signaling that causes conformational changes and redistribution of leukointegrins. Alterations in their shape and distribution are required for firm adhesion of leukocyte integrins to cell molecule adhesion on endothelium. We suggest that integrin CD49d expressed by PBMC and LNC in conjunction with its endothelial ligand CD106, upregulated during orchitis, mediates the firm adhesion step. CCL2 and CCL4 (Guazzone et al. 2009) chemokines are also implicated in the chemotaxis of mononuclear cells into the inflamed testis. These conclusions are supported by the following evidence: 1 ) the highest levels of CCL2 and CCL4 are detected during orchitis; and 2) the number of CCR2+ and CCR5+ cells infiltrating the testicular interstitium increases during the development of EAO. Finally, after firm adhesion transendothelial migration or diapedesis could be mediated by CD106 and CD31. There is increasing evidence that blocking CD31 suppressed inflammation in murine models of neuroinflammation, experimental colitis, and arthritis (Dasgupta et al. 2010).

\section{Materials and Methods}

\section{Animals}

Male Sprague-Dawley rats aged $50-60$ days were kept at $22{ }^{\circ} \mathrm{C}$ with $14 \mathrm{~h}$ light: $10 \mathrm{~h}$ darkness schedule and fed standard food pellets and water ad libitum. The animals were killed according to protocols for animal use following NIH guidelines for care and use of experimental animals.

\section{Immunization schedule}

Rats of the E group were immunized with testicular homogenate (TH) prepared as previously described (Doncel et al. 1989). Briefly, rat testes were decapsulated, diluted in an equal volume of saline, and disrupted in an Omni mixer for $30 \mathrm{~s}$. The final concentration was $500 \mathrm{mg} / \mathrm{ml}$ wet weight (ww). E group rats were injected three times with $200 \mathrm{mg}(\mathrm{ww})$ of TH/dose/rat, on days 0,15 , and 30 . Antigen $(0.4 \mathrm{ml})$ emulsified with $0.4 \mathrm{ml}$ complete Freund's adjuvant (CFA, Sigma-Aldrich) was injected intradermally in footpads and at multiple sites near ganglionar regions. The first two immunizations were followed by an i.v. injection of $0.5 \mathrm{ml}$ Bordetella pertussis (Bp) (strain 10536; Administración Nacional de Laboratorios e Institutos de Salud (A.N.L.I.S). 'Carlos G. Malbrán', Buenos Aires, Argentina) containing $10^{10}$ microorganisms and the third one by an i.p. injection of $10^{9}$ microorganisms. C group rats were injected with an emulsion of saline and CFA, and Bp was used in the same conditions as the E group. $\mathrm{E}, \mathrm{C}$, and $\mathrm{N}$ untreated rats were killed on different days $(7,30,50$, and 100) after the first immunization. Blood was collected and sera stored at $-70{ }^{\circ} \mathrm{C}$ until use. Testes were removed, fixed in Bouin's solution, and embedded in paraffin or quickly frozen for cryostat sections or processed for EC and macrophage isolation or for obtaining TF. Popliteal LN were removed for leukocyte isolation.

Table 3 Leukocyte chemotaxis to CCL3.

\begin{tabular}{lcc}
\hline Days $^{\mathrm{a}}$ & LNC & PBMC \\
\hline 50 & $1.23 \pm 0.27$ & $1.51 \pm 0.30$ \\
100 & $2.69 \pm 0.42$ & $2.19 \pm 0.56$ \\
\hline
\end{tabular}

Migration was calculated by dividing the average number of cells migrated toward the chemokine by the average number of cells migrated toward medium alone. Values are means \pm S.E.M. of 6 rats/group per day. LNC, lymph node cells; PBMC, peripheral blood mononuclear cells.

${ }^{\mathrm{a}}$ Days after first immunization. 

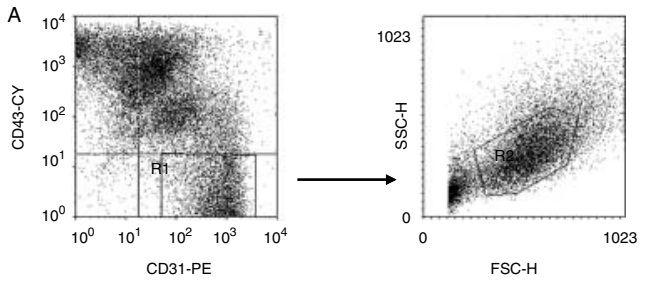

B

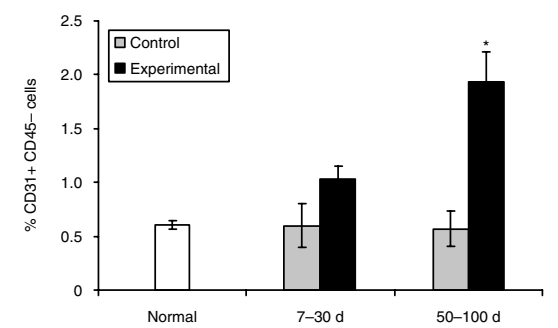

C
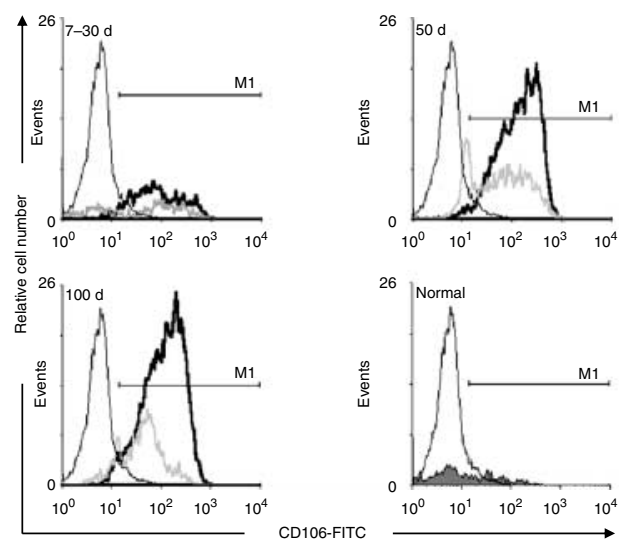

Figure 7 FACS analysis of testicular CD31+ EC expressing CD106. (A) Representative dot plot shows gating on CD31+ CD45- population (R1). R2 shows FSC vs SSC of R1 subpopulation. (B) Quantitative assessment of testicular CD31+ CD45- cells from N, C, and E groups. Values are means \pm s.E.M. of 6 rats/group per day (d) after the first immunization. ${ }^{*} P<0.05 \mathrm{vs} \mathrm{N}$, respective $\mathrm{C}$, and $\mathrm{C}$ and $\mathrm{E} 7-30$ days. (C) Representative histogram overlays show CD106 expression on CD31+ CD45- EC. E group (thicker lines), C group (grey lines) and background staining levels assessed by using irrelevant mouse immunoglobulins (thinner lines).

\section{Histopathology}

The histopathology of testes was studied in paraffin sections obtained from three different levels and stained with hematoxylin-eosin. Quantification of blood vessels was performed by light microscopy with a $12.5 \times$ ocular fitted with a quadratic grid and a $25 \times$ objective. Data were obtained from 6 rats/group per day after first immunization. Two sections per rat were counted and results expressed as the number of vessels per 100 ST cross sections. For comparison of $\mathrm{C}$ and $\mathrm{E}$ rats, this parameter is more precise than quantifying the number of vessels per section surface since ST diameter is different in $\mathrm{N}$ and $\mathrm{C}$ rats compared to EAO rats. No distinction was drawn between arterioles, venules, and capillaries.

\section{Collection of TF}

TF was obtained as previously described by Sharpe et al. (1984) with minor modifications. Briefly, testes were carefully decapsulated and TF was collected for $16 \mathrm{~h}$ at $4{ }^{\circ} \mathrm{C}$ in the presence of protease inhibitors $(1 \mathrm{mM}$ PMSF and $10 \mu \mathrm{g} / \mathrm{ml}$ aprotinin; Sigma-Aldrich). TF were stored at $-70^{\circ} \mathrm{C}$ up to be used.

\section{Preparation of testicular interstitial cell suspension}

Rats from N, C, and E groups were perfused with cold sterile saline solution until tissues were pale. Decapsulated testes were incubated with collagenase $(0.25 \mathrm{mg} / \mathrm{ml}$; Worthington Biochemical Corp., Freehold, NJ, USA) in PBS containing 0.1\% BSA (Sigma-Aldrich Co.) at $34{ }^{\circ} \mathrm{C}$ for $15 \mathrm{~min}$ in a Dubnoff shaking water bath. Collagenase was inactivated by adding ice-cold PBS and STs were allowed to settle for $4 \mathrm{~min}$. Then the supernatant was centrifuged at $300 \mathrm{~g}$ for $10 \mathrm{~min}$ at $4{ }^{\circ} \mathrm{C}$. The pellet was resuspended in PBS and processed directly for culture of macrophages or isolation of EC.

\section{Isolation and culture of testicular macrophages}

The isolation procedure was similar to one described by Yee \& Hutson (1983) with minor modifications (Suescun et al. 2000). Testicular interstitial cell suspensions from $\mathrm{C}$ and $\mathrm{E}$ rats were plated on 35-mm diameter polystyrene Petri dishes (Nunc, Inc., Naperville, IL, USA; $2 \mathrm{ml} /$ plate) and on round coverslips placed on 24 well plates and incubated at $34{ }^{\circ} \mathrm{C}$ for $6-10 \mathrm{~min}$. Dishes and plates were rinsed several times with PBS to remove unattached cells. Cells attached to coverslips were fixed with $2 \%$ paraformaldehyde for immunofluorescent technique. In order to obtain TMCM cells attached to the dishes they were cultured in Medium 199 (M199; Sigma-Aldrich Co.) plus antibiotic-antimycotic solution $(100 \mathrm{U} / \mathrm{ml}$ penicillin G, $100 \mu \mathrm{g} / \mathrm{ml}$ streptomycin sulfate, $0.25 \mu \mathrm{g} / \mathrm{ml}$ amphotericin B, 15240-096; Gibco, Grand Island, NY, USA) for $20 \mathrm{~h}$ at $34^{\circ} \mathrm{C}$ in a humidified atmosphere with $5 \% \mathrm{CO}_{2}$. Adherent cells were harvested and counted with trypan blue to determine the number of cells per plate and viability. Purity of macrophage preparations was $90 \%$ evaluated by latex bead phagocytosis and ED1 plus ED2 immunohistochemistry.

\section{Preparation of TMCM}

TMCM were collected from cultures of testicular macrophages with a Pasteur pipette in sterile conditions, centrifuged at $2000 \mathrm{~g}$ for $10 \mathrm{~min}$ and stored at $-70{ }^{\circ} \mathrm{C}$ prior to $\mathrm{CCL} 3$ determination by ELISA.

\section{ELISA for rat CCL3}

CCL3 concentrations in TF, TMCM, and serum were quantified using an ELISA as follows. Flat-bottom 96 well microtiter plates (Immunlon 2HB, Thermo Electron Corp., Waltham, MA, USA) were coated with $100 \mu \mathrm{l} /$ well of the samples (diluted $1 / 2$ in $50 \mathrm{mM}$ carbonate buffer $(\mathrm{pH}=9)$ containing $0.5 \%$ inactivated fetal bovine serum (FBS) overnight at $4{ }^{\circ} \mathrm{C}$. Microtiter plate 
A
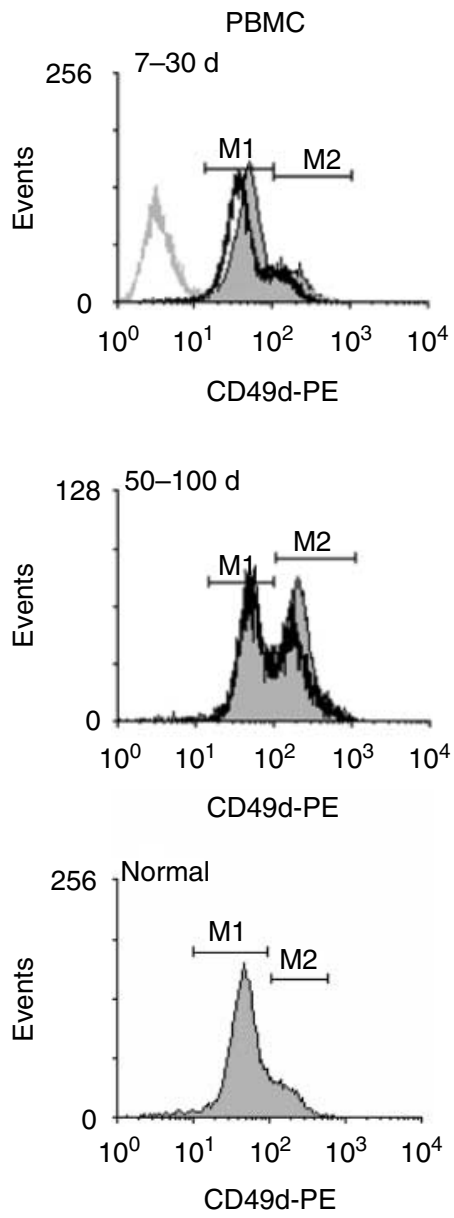

B

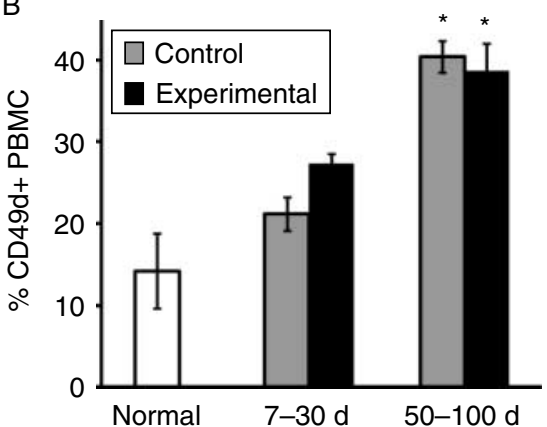

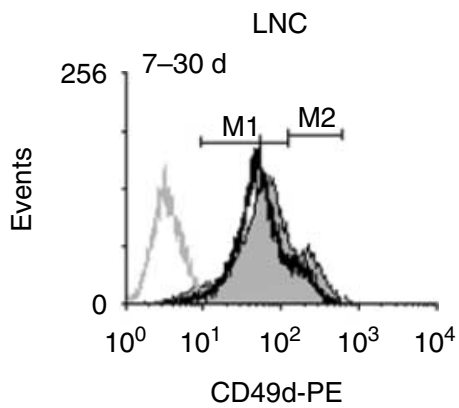
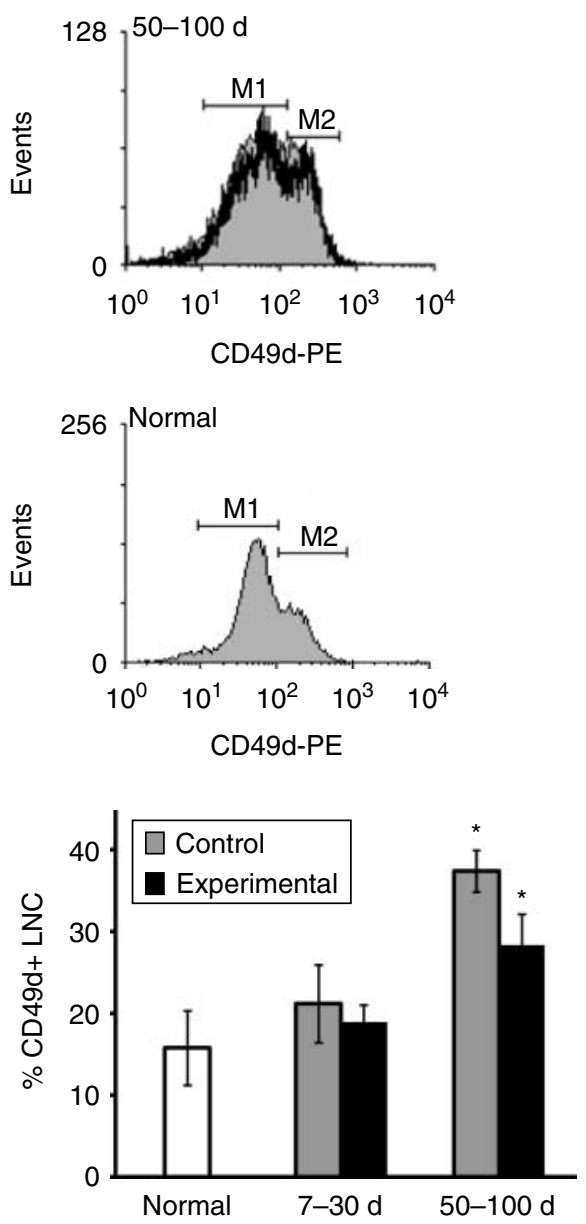

Figure $8 \mathrm{CD} 49 \mathrm{~d}$ expression on the surface of PBMC and LNC isolated from $\mathrm{C}$ and $\mathrm{E}$ rats on different days (d) after the first immunization. (A) Representative histogram overlays demonstrating CD49d expression. E group (thicker black lines), C group (grey bold histogram) and background staining levels assessed by using irrelevant mouse immunoglobulins (thinner grey lines). The same negative background levels were observed in cells isolated from rats killed on days 7-30 and 50-100. (B) Quantitative assessment of the percentage of CD49d+ cells from PBMC and LNC by FACS analysis was performed on M2 subset (CD49d ${ }^{\text {high }}$ cells). Values are means \pm S.E.M. of 6 rats/group per day after the first immunization. ${ }^{*} P<0.05$ vs $\mathrm{C}$ and $\mathrm{E} 7-30$ days. nonspecific binding sites were blocked with $1 \%$ BSA in PBS and incubated for $90 \mathrm{~min}$ at room temperature. Plates were washed with PBS with $0.02 \%$ azide, and incubated with a primary monoclonal anti-rat MIP-1 $\alpha($ CCL3) antibody $(1 / 100$ in PBS 1\% BSA, $100 \mu \mathrm{l} /$ well; Biosource International, Inc., Camarillo, CA, USA) for $90 \mathrm{~min}$ at room temperature. After three washes with PBS containing $0.05 \%$ Tween (wash buffer), $100 \mu \mathrm{l} /$ well of biotinylated antibody $(10 \mu \mathrm{g} / \mathrm{ml}$ in PBS $1 \%$ BSA with $0.1 \%$ Tween; Vector Laboratories, Burlingame, CA, USA) were added, followed by $90 \mathrm{~min}$ incubation at room temperature. Plates were washed three times and incubated for $60 \mathrm{~min}$ with $100 \mu \mathrm{l} /$ well alkaline phosphatase streptavidin $(1 / 200$ in $10 \mathrm{mM}$ HEPES, $0.15 \mathrm{M} \mathrm{NaCl}, 0.1 \mathrm{mg} / \mathrm{ml}$ BSA;
Vector Laboratories) and then washed. Color development proceeded by incubating the plates with substrate solution ( $p$ nitrophenyl phosphate; Sigma Chemical Co.) for $30 \mathrm{~min}$ and stopped by addition of $0.1 \mathrm{M}$ EDTA ( $\mathrm{pH}$ 7.5). Absorbance at $405 \mathrm{~nm}$ was determined by a microplate reader (Bio-Rad). CCL3 concentration was calculated from a standard curve prepared for this purpose.

\section{Isolation of leukocytes}

Popliteal LN and peripheral blood were obtained from N, C, and $E$ rats. $L N$ were cut with scissors into small pieces in PBS $0.1 \mathrm{M}, \mathrm{pH} 7.2$ with $0.03 \%$ azide plus $10 \%$ FBS and sieved 
through a stainless steel mesh. The cell suspension was quickly passed through a syringe with nylon wool at room temperature in order to deplete it of dead cells and fat tissue. PBMC were purified by Ficoll-Hypaque gradient centrifugation. Cells from both samples were then centrifuged and counted in a hemocytometer and viability was assessed by trypan blue exclusion.

\section{In vitro chemotaxis assay}

Migration of leukocytes was assessed in 24 well transwell chambers equipped with $5 \mu \mathrm{m}$ pore polycarbonate Transwell culture inserts (Corning Incorp., Acton, MA, USA). LNC and PBMC at $2 \times 10^{6} /$ insert in assay media (50\% M199: 50\% RPMI1640 (Sigma-Aldrich Co.), and $0.5 \%$ BSA) were added to duplicate upper wells, CCL3 $(100 \mathrm{ng} / \mathrm{ml})$ or control media placed into the wells and the assembled plates incubated at $37^{\circ} \mathrm{C}, 5 \% \mathrm{CO}_{2}$ for $4 \mathrm{~h}$. Leukocytes which migrated into the bottom wells were resuspended and then counted with trypan blue (only viable leukocytes migrated through the membrane; Ebert 1998). Migration was calculated by dividing the average number of cells migrated toward the chemokine by the average number of cells migrated toward medium alone (migration rate).

\section{Immunohistochemistry}

Cryostat sections (6 $\mu \mathrm{m}$ thick) were fixed in cold acetone. An immunoperoxidase technique using the avidin-biotin system (ABC Vectastain kit; Vector Laboratories) was applied. Sections were washed in PBS and incubated with 5\% skim milk, $0.01 \%$ Triton X-100, and then treated with avidin-biotin blocking solution (Vector Laboratories). After incubation with primary antibodies anti-rat CCR5 $(10 \mu \mathrm{g} / \mathrm{ml}$; Santa Cruz Biotechnology, Inc., Santa Cruz, CA, USA) or anti-rat CCR1 (5 $\mu \mathrm{g} / \mathrm{ml}$; Santa Cruz Biotechnology, Inc.) sections were incubated with biotinylated anti-goat Ig (Vector Laboratories). Endogenous peroxidase activity was blocked by treatment with $0.3 \% \mathrm{H}_{2} \mathrm{O}_{2}$ in methanol for $30 \mathrm{~min}$. Then the reaction was amplified with an $A B C$ Vectastain kit and the 3,3'-diaminobenzidine- $\mathrm{H}_{2} \mathrm{O}_{2}$ (DAB Substrate kit; Vector Laboratories) was used as peroxidase substrate. Sections were counterstained with hematoxylin. Negative controls were obtained by incubating sections with isotype IgG control instead of primary antibodies. CCR5- or CCR1-positive cells were counted using a $40 \times$ objective. The total number of fields counted for each section was 40, and 3 animals/group/day after first immunization were analyzed. The number of CCR5+ or CCR1+ cells per unit volume testis was calculated by morphometry, as previously described (Suescun et al. 2003) using the Floderus Default (Floderus 1944). Illustration of CCR5+ cells was published in our previous report on chemokines (Guazzone et al. 2009) since CCR5 is also the receptor for CCL4. The original result of this paper is the quantification of CCR5+ cells during the development of EAO.

\section{Double immunofluorescence technique}

In order to detect CCR5 in $\mathrm{ED}^{+}$or $\mathrm{ED}^{+}{ }^{+}$testicular macrophages a double immunofluorescent technique was used. A mouse mAb, ED1, which recognizes a cytoplasmic antigen in rat monocytes, macrophages, and dendritic cells, and a mouse mAb, ED2, which recognizes a membrane antigen of tissue macrophages were used to identify circulating and resident macrophages respectively. Isolated testicular macrophages seeded on glass coverslips were fixed in $2 \%$ formaldehyde for $10 \mathrm{~min}$ and permeabilized with $0.1 \%$ Triton$X 100$ in PBS. Cells were washed three times with PBS, a procedure repeated after each of the following steps. Nonspecific binding sites were blocked by treating the cells with $5 \%$ normal goat serum in $3 \%$ BSA in PBS for 30 min at room temperature. Cells were then reacted with anti rat CCR5 $(10 \mu \mathrm{g} / \mathrm{ml})$ followed by an anti goat Rhodamine (Rhod) conjugated-IgG (1:100; Santa Cruz Biotechnology, Inc.) in $5 \%$ normal rat serum. Then, for macrophage subset identification, cells were incubated with primary antibodies ED1 $(10 \mu \mathrm{g} / \mathrm{ml})$ or ED2 $(5 \mu \mathrm{g} / \mathrm{ml}$; BD Pharmingen, San Jose, CA, USA) in PBS with $0.03 \%$ Triton-X 100 and 5\% normal rat serum, followed by an anti mouse FITC conjugated-IgG (1:50; Vector Laboratories) in PBS with $0.03 \%$ Triton-X 100 and 5\% normal rat serum. Controls were obtained by replacing the first antibodies with PBS or IgG isotype. Coverslips were mounted with $90 \%$ glycerine in PBS and observed using epifluorescence optics with an Axiophot microscope (100× objective).

\section{Isolation and characterization of EC from rat testis}

EC were enriched from testicular interstitial cell suspension by positive selection using primary PE conjugated anti-rat CD31 (PECAM-1) antibody (BD Pharmingen), followed by incubation with the secondary anti-phycoerythrin (PE) antibody coupled magnetic beads according to the manufacturer's protocol (Miltenyi Biotec, Bergish Gladbach, Germany). Subsequently, enriched EC populations were stained with the primary mouse anti rat CD106 (VCAM- 1$)$ antibody $\left(1 \mu \mathrm{g} / 1 \times 10^{6}\right.$ cells; BD Pharmingen) followed by incubation with the secondary FITC conjugated anti-mouse IgG antibody (1:40; Vector Laboratories) for $30 \mathrm{~min}$. Cells were washed with PBS/BSA buffer and stained for $30 \mathrm{~min}$ with anti-rat $\mathrm{mAb}$ CD45 conjugated with PE-Cy5 $\left(0.5 \mu \mathrm{g} / 1 \times 10^{6}\right.$ cells; BD Pharmingen). Finally, cells were washed with PBS/BSA buffer and fixed with $0.5 \%$ paraformaldehyde. Background staining was evaluated using isotype controls: PE or PE-Cy5 -conjugated mouse $\operatorname{lgG}_{1, \mathrm{k}} \mathrm{mAb}$ or mouse $\operatorname{lgG}_{1, \mathrm{k}} \mathrm{mAb}$ (BD Pharmingen). The whole procedure was done at $4{ }^{\circ} \mathrm{C}$. Samples were run on a FACSCalibur flow cytometer (BD Bioscience, San Diego, CA, USA). CD106 expression analysis was done on CD31+ CD45- cells.

\section{CD49d expression in lymphomonocytes (flow cytometry)}

CD49d (integrin $\alpha_{4}$ chain) expression was analyzed by flow cytometry in PBMC and LNC. $2 \times 10^{6}$ cells from both samples were incubated with primary $\mathrm{mAb}$ mouse anti rat CD49d $\left(0.5 \mu \mathrm{g} / 1 \times 10^{6}\right.$ cells; BD Pharmingen) for $30 \mathrm{~min}$. After washing in cold PBS with $10 \%$ FBS (PBS/FBS), cells were incubated with anti mouse PE conjugated-IgG (1:40; Dakocytomation, Carpinteria, CA, USA), for $30 \mathrm{~min}$. Then, cells were washed twice with PBS/FBS. The whole procedure was done at 
$4{ }^{\circ} \mathrm{C}$. The total lymphomonocyte fraction was analyzed and background threshold levels were set using irrelevant mouse immunoglobulins ( $\operatorname{lgG}_{2 \mathrm{~A}} \kappa ;$ BD Pharmingen).

\section{Statistical analysis}

For statistical evaluations the nonparametric Mann-Whitney rank test was used. A value of $P \leq 0.05$ was considered significant.

\section{Declaration of interest}

The authors declare that there is no conflict of interest that could be perceived as prejudicing the impartiality of the research reported.

\section{Funding}

This work was supported by grants from the Agencia Nacional de Promoción Científica y Tecnológica (ANPCyT), the Consejo Nacional de Promoción Científica y Tecnológica (CONICET), and from the Universidad de Buenos Aires. P Jacobo is a fellow of the CONICET. The other authors are research members of the CONICET.

\section{Acknowledgements}

We thank the Instituto Nacional de Microbiología 'A Malbrán,' División Vacunas Bacterianas, for their generous donation of Bordetella pertussis.

\section{References}

Aubry F, Habasque C, Satie AP, Jégou B \& Samson M 2000 Expression and regulation of the CC-chemokine monocyte chemoattractant protein-1 in rat testicular cells in primary culture. Biology of Reproduction 62 1427-1435. (doi:10.1095/biolreprod62.5.1427)

Chui R \& Dorovini-Zis K 2010 Regulation of CCL2 and CCL3 expression in human brain endothelial cells by cytokines and lipopolysaccharide. Journal of Neuroinflammation 7 1. (doi:10.1186/1742-2094-7-1)

Collin O \& Bergh A 1996 Leydig cells secrete factors which increase vascular permeability and endothelial cell proliferation. International Journal of Andrology 19 221-228. (doi:10.1111/j.1365-2605.1996.tb00466.x)

Cook-Mills JM, Marchese M \& Abdala-Valencia H 2010 VCAM-1 expression and signaling during disease: regulation by reactive oxygen species and antioxidants. Antioxidants \& Redox Signaling 15 1607-1638 (doi:10.1089/ars.2010.3522).

Dasgupta B, Chew T, deRoche A \& Muller WA 2010 Blocking platelet/endothelial cell adhesion molecule 1 (PECAM) inhibits disease progression and prevents joint erosion in established collagen antibodyinduced arthritis. Experimental and Molecular Pathology 88 210-215. (doi:10.1016/j.yexmp.2009.09.013)

Doncel GF, Di Paola JA \& Lustig L 1989 Sequential study of the histopathology and cellular and humoral immune response during the development of an autoimmune orchitis in Wistar rats. American Journal of Reproductive Immunology 20 44-51.

Ebert EC 1998 Tumor necrosis factor- $\alpha$ enhances intraepithelial lymphocyte proliferation and migration. Gut 42 650-655. (doi:10.1136/gut.42.5. 650)

Floderus S 1944 Untersuchungen uber den Bau der menschlichen Hypophyse mit besonderer Berucksihtigung der quantitativen mikromorphologischen Verhaltnisse. Acta Pathologica, Microbiologica et Immunologica Scandinavica 53 1-276.
Golat BT \& Cameron DF 2008 Sertoli cells enhance formation of capillarylike structures in vitro. Cell Transplantation 17 1135-1144. (doi:10.3727/ 096368908787236512)

Guazzone VA, Rival C, Denduchis B \& Lustig L 2003 Monocyte chemoattractant protein-1 (MCP-1/CCL2) in experimental autoimmune orchitis. Journal of Reproductive Immunology 60 143-157. (doi:10. 1016/j.jri.2003.08.001)

Guazzone VA, Denduchis B \& Lustig L 2005 Involvement of CD44 in leukocyte recruitment to the rat testis in experimental autoimmune orchitis. Reproduction 129 603-609. (doi:10.1530/rep.1.00329)

Guazzone VA, Jacobo P, Theas MS \& Lustig L 2009 Cytokines and chemokines in testicular inflammation: a brief review. Microscopy Research and Technique 72 620-628. (doi:10.1002/jemt.20704)

Hakovirta H, Vierula M, Wolpe SD \& Parvinen M 1994 MIP-1 alpha is a regulator of mitotic and meiotic DNA synthesis during spermatogenesis. Molecular and Cellular Endocrinology 99 119-124. (doi:10.1016/03037207(94)90154-6)

Jacobo P, Guazzone VA, Jarazo-Dietrich S, Theas MS \& Lustig L 2009 Differential changes in CD4 + and CD8 + effector and regulatory $T$ lymphocyte subsets in the testis of rats undergoing autoimmune orchitis. Journal of Reproductive Immunology 81 44-54. (doi:10.1016/j.jri.2009. 04.005)

Jacobo P, Guazzone VA, Theas MS \& Lustig L 2011a Testicular autoimmunity. Autoimmunity Reviews 10 201-204. (doi:10.1016/ j.autrev.2010.09.026)

Jacobo PV, Pérez CV, Theas MS, Guazzone VA \& Lustig L 2011 b CD4 + and CD8 $+\mathrm{T}$ cells producing Th1 and Th17 cytokines are involved in the pathogenesis of autoimmune orchitis. Reproduction 141 249-258. (doi:10.1530/REP-10-0362)

Jarazo Dietrich S, Jacobo P, Perez C, Lustig L \& Theas MS 2010 Upregulation of nitric oxide-nitric oxide synthase system in the testis of rats with autoimmune orchitis. International Journal of Andrology 3382 . (doi:10.1111/j.1365-2605.2010.01105.x)

Kennedy KJ, Strieter RM, Kunkel SL, Lukacs NW \& Karpus WJ 1998 Acute and relapsing experimental autoimmune encephalomyelitis are regulated by differential expression of the CC chemokines macrophage inflammatory protein-1alpha and monocyte chemotactic protein-1. Journal of Neuroimmunology 92 98-108. (doi:10.1016/S0165-5728(98)00187-8)

Langer HF \& Chavakis T 2009 Leukocyte-endothelial interactions in inflammation. Journal of Cellular and Molecular Medicine 13 1211-1220. (doi:10.1111/j.1582-4934.2009.00811.x)

Lustig L 1998 Papel de las moléculas de adhesión en auto-inmunidad. Modelo experimental de orquitis autoinmune. Medicina 58576.

Mayerhofer A, Sinha Hikim AP, Bartke A \& Russell LD 1989 Changes in the testicular microvasculature during photoperiod-related seasonal transition from reproductive quiescence to reproductive activity in the adult golden hamster. Anatomical Record 224 495-507. (doi:10.1002/ar.1092240407)

Meinhardt A \& Hedger MP 2011 Immunological, paracrine and endocrine aspects of testicular immune privilege. Molecular and Cellular Endocrinology 335 60-68. (doi:10.1016/j.mce.2010.03.022)

Muller WA 2011 Mechanisms of leukocyte transendothelial migration. Annual Review of Pathology: Mechanisms of Disease 6 323-344. (doi:10.1146/annurev-pathol-011110-130224)

Ransohoff RM 2009 Chemokines and chemokine receptors: standing at the crossroads of immunobiology and neurobiology. Immunity 31 711-721. (doi:10.1016/j.immuni.2009.09.010)

Rival C, Lustig L, losub R, Guazzone VA, Schneider E, Meinhardt A \& Fijak M 2006 a Identification of a dendritic cell population in normal testis and in chronically inflamed testis of rats with autoimmune orchitis. Cell and Tissue Research 324 311-318. (doi:10.1007/s00441-005-0129-5)

Rival C, Theas MS, Guazzone VA \& Lustig L 2006 $b$ Interleukin-6 and IL-6 receptor cell expression in testis of rats with autoimmune orchitis. Journal of Reproductive Immunology 70 43-58. (doi:10.1016/j.jri.2005.10.006)

Rival C, Theas MS, Suescun MO, Jacobo P, Guazzone V, van Rooijen N \& Lustig L 2008 Functional and phenotypic characteristics of testicular macrophages in experimental autoimmune orchitis. Journal of Pathology 215 108-117. (doi:10.1002/path.2328)

Sainio-Pöllänen $S$, Sundström J, Erkkilä $S$, Hänninen $A$, Vainiopää $M$, Martikainen M, Salminen E, Veräjänkorva E, Antola H, Nikula $\mathrm{H}$ et al. 1997 CD106 (VCAM-1) in testicular immunoregulation. Journal of Reproductive Immunology 33 221-238. (doi:10.1016/S0165-0378(97) 00024-7) 
Sharpe RM, Cooper I \& Doogan DG 1984 Increase in Leydig cell responsiveness in the unilaterally cryptorchid rat testis and its relationship to the intratesticular levels of testosterone. Journal of Endocrinology 102 319-327. (doi:10.1677/joe.0.1020319)

Suescun MO, Calandra RS \& Lustig L 2000 Effect of testicular macrophage conditioned media from rats with autoimmune orchitis on Leydig cell function. American Journal of Reproductive Immunology 43 116-123. (doi:10.1111/j.8755-8920.2000.430208.x)

Suescun MO, Rival C, Theas MS, Calandra RS \& Lustig L 2003 Involvement of tumor necrosis factor-alpha in the pathogenesis of autoimmune orchitis in rats. Biology of Reproduction 68 2114-2121. (doi:10.1095/ biolreprod.102.011189)

Szekanecz Z, Halloran MM, Violin MV, Woods JM, Strieter RM, Haines GK III, Kunkel SL, Burdick MD \& Koch AE 2000 Temporal expression of inflammatory cytokines and chemokines in rat adjuvant-induced arthritis. Arthritis \& Rheumatism 43 1266-1277. (doi:10.1002/15290131(200006)43:6<1266::AID-ANR9>3.0.CO;2-P)

Thelen M \& Stein JV 2008 How chemokines invite leukocytes to dance. Nature Immunology 9 953-959. (doi:10.1038/ni.f.207)
Tung KSK, Fusi F \& Teuscher C 2000 Autoimmune disease of the spermatozoa, ovary and testis. In The Molecular Pathology of Autoimmune Disease, pp 1031-1045. Eds AN Theofilopoulos \& CA Bona. New York, NY: Taylor \& Francis.

Veräjäkorva E, Laato M \& Pöllänen P 2002 CD 99 and CD 106 (VCAM-1) in human testis. Asian Journal of Andrology 4 243-248.

Yee JB \& Hutson JC 1983 Testicular macrophages: isolation, characterization and hormonal responsiveness. Biology of Reproduction 29 1319-1326. (doi:10.1095/biolreprod29.5.1319)

Zlotnik A \& Yoshie O 2000 Chemokines: a new classification system and their role in immunity. Immunity 12 121-127. (doi:10.1016/S10747613(00)80165-X)

Received 15 March 2011

First decision 3 May 2011

Revised manuscript received 18 January 2012

Accepted 20 February 2012 